OPEN ACCESS

Edited by:

Haitao Shi,

Hainan University, China

Reviewed by:

Yang-Dong Guo,

China Agricultural University, China

Shan Yuan,

China Agricultural University, China

*Correspondence:

Praveen K. Saxena psaxena@uoguelph.ca

Specialty section:

This article was submitted to

Plant Cell Biology,

a section of the journal

Frontiers in Plant Science

Received: 15 September 2016 Accepted: 02 November 2016 Published: 16 November 2016

Citation:

Erland LAE, Chattopadhyay A Jones AMP and Saxena PK (2016) Melatonin in Plants and Plant Culture

Systems: Variability, Stability and Efficient Quantification.

Front. Plant Sci. 7:1721. doi: $10.3389 /$ fpls.2016.01721

\section{Melatonin in Plants and Plant Culture Systems: Variability, Stability and Efficient Quantification}

\author{
Lauren A. E. Erland, Abhishek Chattopadhyay, Andrew Maxwell P. Jones and \\ Praveen K. Saxena* \\ Department of Plant Agriculture, Gosling Institute for Plant Preservation, University of Guelph, Guelph, ON, Canada
}

Despite growing evidence of the importance of melatonin and serotonin in the plant life, there is still much debate over the stability of melatonin, with extraction and analysis methods varying greatly from lab to lab with respect to time, temperature, light levels, extraction solvents, and mechanical disruption. The variability in methodology has created conflicting results that confound the comparison of studies to determine the role of melatonin in plant physiology. We here describe a fully validated method for the quantification of melatonin, serotonin and their biosynthetic precursors: tryptophan, tryptamine and $\mathrm{N}$-acetylserotonin by liquid chromatography single quadrupole mass spectrometry (LC-MS) in diverse plant species and tissues. This method can be performed on a simple and inexpensive platform, and is both rapid and simple to implement. The method has excellent reproducibility and acceptable sensitivity with percent relative standard deviation (\%RSD) in all matrices between 1 and 10\% and recovery values of $82-113 \%$ for all analytes. Instrument detection limits were $24.4 \mathrm{ng} / \mathrm{mL}$, $6.10 \mathrm{ng} / \mathrm{mL}, 1.52 \mathrm{ng} / \mathrm{mL}, 6.10 \mathrm{ng} / \mathrm{mL}$, and $95.3 \mathrm{pg} / \mathrm{mL}$, for serotonin, tryptophan, tryptamine, $\mathrm{N}$-acetylserotonin and melatonin respectively. Method detection limits were $1.62 \mu \mathrm{g} / \mathrm{g}, 0.407 \mu \mathrm{g} / \mathrm{g}, 0.101 \mu \mathrm{g} / \mathrm{g}, 0.407 \mu \mathrm{g} / \mathrm{g}$, and $6.17 \mathrm{ng} / \mathrm{g}$ respectively. The optimized method was then utilized to examine the issue of variable stability of melatonin in plant tissue culture systems. Media composition (Murashige and Skoog, Driver and Kuniyuki walnut or Lloyd and McCown's woody plant medium) and light (16 h photoperiod or dark) were found to have no effect on melatonin or serotonin content. A Youden trial suggested temperature as a major factor leading to degradation of melatonin. Both melatonin and serotonin appeared to be stable across the first 10 days in media, melatonin losses reached a mean minimum degradation at 28 days of approximately $90 \%$; serotonin reached a mean minimum value of approximately $60 \%$ at 28 days. These results suggest that melatonin and serotonin show considerable stability in plant systems and these indoleamines and related compounds can be used for investigations that span over 3 weeks.

Keywords: degradation, matrix effects, method validation, tissue culture, liquid chromatography-mass spectrometry, serotonin, tryptophan, tryptamine 


\section{INTRODUCTION}

Melatonin (N-acetyl-5-methoxy-tryptamine) is an indoleamine neurohormone, first identified and quantified in plants in 1995 (Dubbels et al., 1995; Hattori et al., 1995). Since then there has been an ever increasing interest in the roles and effects of melatonin in plant systems and it has since been identified as playing important roles in many plant responses including growth, reproduction, development, and stress (Erland et al., 2015; Reiter et al., 2015; Hardeland, 2016). Many of the studies providing insight into these processes rely upon some form of analytical analysis to determine endogenous levels of melatonin in response to a stimulus, treatment or mutation, while treatment often requires prolonged exposure or treatment of plants in in vitro culture or greenhouse studies. Validated methods are an essential requirement for accurate quantification of these compounds, and provides both the reader and author confidence in the validity and reproducibility of the data (Betz et al., 2011). Though research methods are available for serotonin and melatonin in plant tissues (Cao et al., 2006; Pape and Lüning, 2006; Garcia-Parrilla et al., 2009; Jiao et al., 2016), most do not also quantify all four of the major phytomelatonin biosynthetic precursors: serotonin, tryptophan, tryptamine and $\mathrm{N}$-acteylserotonin (NAS).

There is controversy in the literature over the stability of melatonin in plants, with both analytical platform, extraction, and analysis methods varying greatly from one report to another with time, temperature, light levels, extraction solvents and mechanical disruption among others all varying widely (Table 1). This has in turn lead to conflicting results between labs, and has contributed to difficulty in confirming and comparing the results across various labs. This is likely, in part, due to the presence of several papers detailing the stability of melatonin from mammalian research (Cavallo and Hassan, 1995; Daya et al., 2001). Another potentially confounding factor in the field of phytomelatonin analysis, is the presence of melatonin isomers in plant products. Recent studies have hypothesized that as many as forty isomers of melatonin may exist in plants, and the presence of these compounds may explain some of this interlab variability (Tan et al., 2012; Vigentini et al., 2015). Though oftentimes reports define these compounds as simply "melatonin isomer," since the initial report of melatonin isomers in wine (Rodriguez-Naranjo et al., 2011), a system of nomenclature has been proposed by Tan et al. (2012), which defines the isomers by the location of the N-acetylaminoethyl and methoxy side chains, and since then several of these theorized isomers have been identified in plant and fermented plant products, though some controversy still exists on this topic (Gomez et al., 2012,

\footnotetext{
Abbreviations: DKW, Driver and Kuniyuki walnut; ECD, electrochemical detector; ELISA, enzyme linked immunosorbent assay; ESI, electrospray ionization; FLD, fluorescence detection; LLOQ, lower limit of quantification; LN, liquid nitrogen; LOD, limit of detection; $\mathrm{M}$, mechanical grinding; $\mathrm{m} / \mathrm{z}$, mass to charge ratio; MS, mass spectrometry; NAS, N-acetylserotonin; RSD, relative standard deviation; RT, room temp; SIR, single ion recording; SJW, St. John's wort; SPE, solid phase extraction; TLC, thin layer chromatography; ULOQ, upper limit of quantification; UPLC-MS, ultra performance liquid chromatography; UV, ultra violet detection; WPM, Lloyd and McCown's woody plant medium.
}

2013; Gardana et al., 2014; Yilmaz et al., 2014; Iriti and Vigentini, 2015).

Additionally, though many reports have now examined the roles serotonin and melatonin play in plants by employing in vitro plant tissue culture methods, the actual quantity of melatonin and serotonin which are present in the treatment medium has not been characterized. Induction of cell division, differentiation and morphogenesis in plant cultures are highly sensitive to the relative ratios of plant growth regulators (Skoog and Miller, 1957). Both melatonin and serotonin have the potential to mimic, modulate, and modify auxin and cytokinin ratios in tissues grown in vitro (Erland et al., 2015). Variable stability of melatonin and serotonin may lead to a significant difference in their actual content in the medium and within the growing tissues.

This study describes the development of an efficient method for determination of melatonin and its precursors and provides evidence of stability in in vitro culture conditions, which may facilitate investigations of regulation of plant development as influenced by interaction of plant hormones.

\section{MATERIALS AND METHODS}

\section{Sample Matrices}

Eight species were utilized for validation and three sample types root, shoot (including stems and leaves) and seed for a total of 12 matrices: St. John's wort (Hypericum perforatum; SJW) roots and shoots, banana (Musa sp.) roots and shoot, African violet (Saintpaulia sp.) shoots, potato (Solanum tuberosum cv "Shepady") shoots, sweet wormwood (Artemisia annua; Artemisia) shoots and roots, tobacco (Nicotiana tabaccum) shoots and roots and American elm (Ulmus americana) shoots and fennel (Foeniculum vulgare) seeds. Fennel seeds were purchased from a local supermarket in Guelph, Ontario, and all other samples were taken from in vitro grown cultures maintained at $26^{\circ} \mathrm{C}$ under a $16 \mathrm{~h}$ photoperiod.

\section{Design of Method Validation}

Accuracy of the method was evaluated by adding known amounts of a given analyte to a given matrix, and the amount ascertained by the method was determined by correcting for endogenous concentrations present in unspiked matrix to determine deviation from the expected value. Precision was evaluated by calculating the relative standard deviation for all measurements for a particular matrix and analyte at each concentration. No fewer than nine determinations were made on 3 different days, with no $<2$ days separating each set of samples. Accuracy and precision were evaluated across the entire study to ensure method robustness across different days.

Instrument and method limit of detection and limits of quantification were determined according to accepted practices (Bliesner, 2005; AOAC International, 2013), with the limit of detection set to a signal-to-noise ratio of 3:1, and the lower limit of quantitation set to a signal-to-noise of 10:1. 


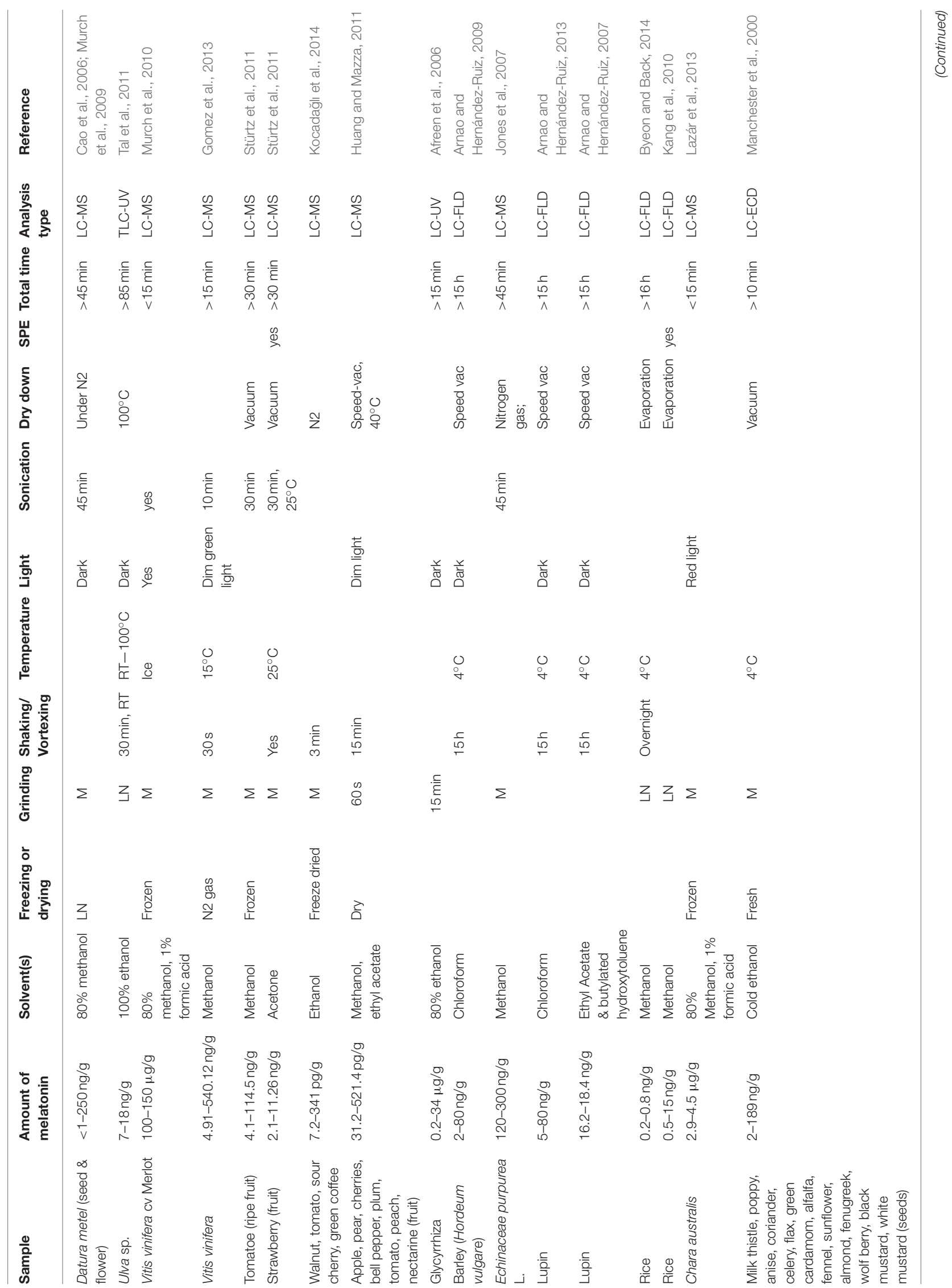




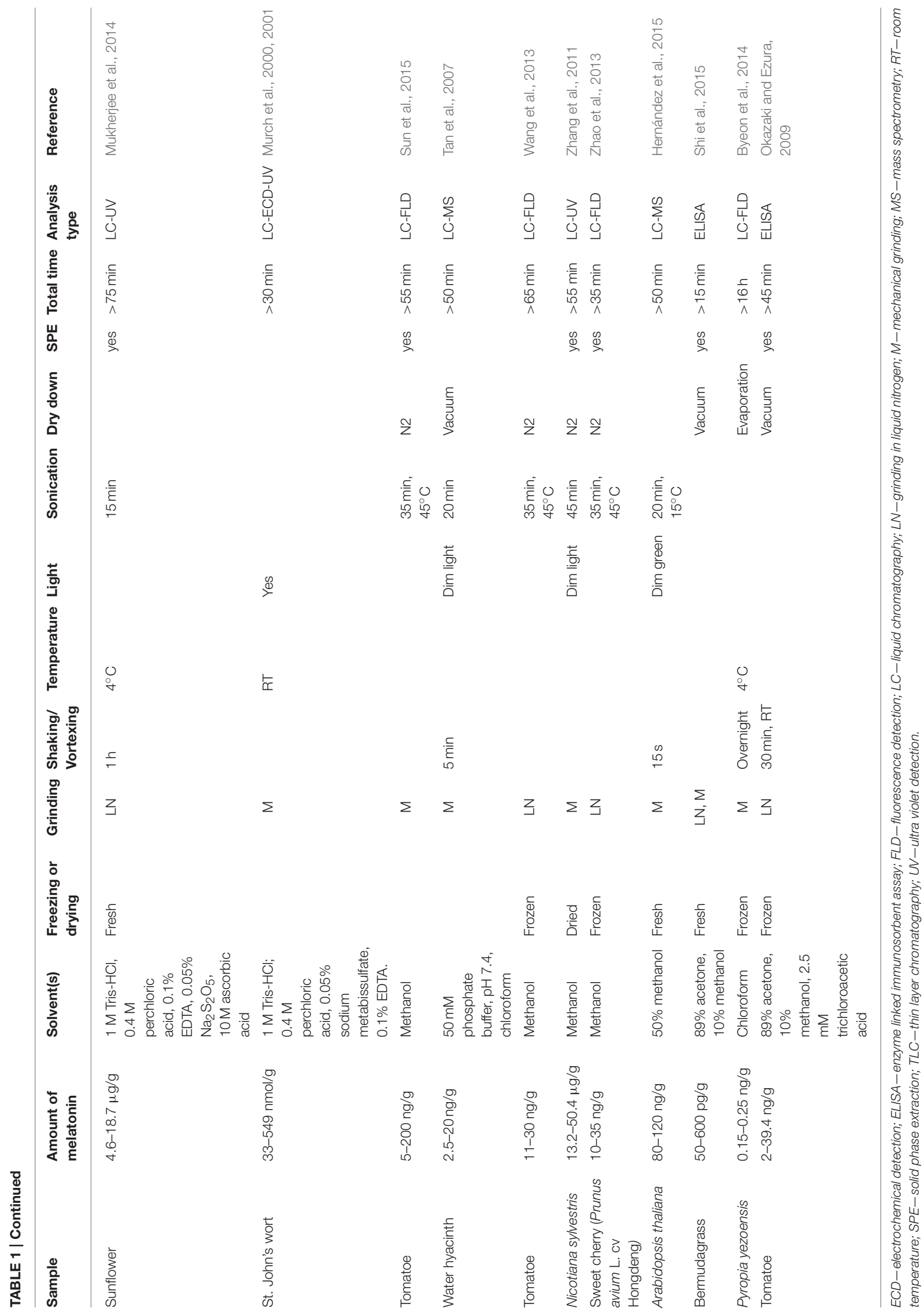




\section{Sample Preparation}

For sample preparation prior to analysis samples $(\sim 150 \mathrm{mg})$ were ground in liquid nitrogen then suspended in $0.5 \mathrm{~mL}$ of extraction solvent which was comprised of 50\% methanol (MS Grade, Fisher Scientific, Canada; $\mathrm{MeOH}$ ) and $4 \%$ acetic acid (glacial, Fisher Scientific, Canada) in Milli-Q water. Extraction solvent was chosen after a literature review (Table 1), and methanol was specifically chosen as it can be directly injected onto a reverse phase chromatography system, as employed in this study, without the need for additional dry down or clean-up steps as required for strong organic solvents such as chloroform or ethyl actetate. Samples were then sonicated (3510R-DTH, Branson, USA) for $15 \mathrm{~min}$ on ice and spun down (2 min, $13000 \mathrm{rpm}$ ) and, supernatant removed. Supernatant was then filtered through a $0.45 \mu \mathrm{M}$ centrifuge filter (Millipore; $1 \mathrm{~min}, 130000 \mathrm{rpm}$ ) and the flow through was diluted ten times in $10 \mathrm{mM} \mathrm{pH} \mathrm{9,} \mathrm{adjusted} \mathrm{with}$ ammonium hydroxide (Sigma Aldrich, Canada). Prior to analysis samples were either left unspiked or spiked with a high or low concentration of mixed standard containing either $0.5 \mu \mathrm{g} / \mathrm{mL}$ or $5 \mu \mathrm{g} / \mathrm{mL}$ melatonin, serotonin, tryptamine, tryptophan, and NAS, for a total of three sample groups. All standards were analytical grade and purchased from Sigma Aldrich, Canada.

\section{Detection and Quantification}

For quantification of samples by liquid chromatographymass spectrometry, $3 \mu \mathrm{L}$ of sample was injected onto a Waters Acquity BEH Column $(2.1 \times 50 \mathrm{~mm}$, i.d. $2.1 \mathrm{~mm}$, $1.7 \mu \mathrm{m})$ on a Waters Acquity Classic ultra-performance liquid chromatography (UPLC) system (binary UPLC, Waters, Canada) with single quadrupole mass spectrometer (MS) detection (Waters, QDa performance model, Waters, Canada). Samples were run on a gradient with $\mathrm{A}-10 \mathrm{mM}$ ammonium acetate $\mathrm{pH}$ 9, adjusted with ammonium hydroxide; $\mathrm{B}-100 \% \mathrm{MeOH}$ with initial conditions of $95 \%$ A $5 \%$ B increased to 5\% A 95\% B over $4.5 \mathrm{~min}$ using an Empower curve of 8. Column temperature was $40^{\circ} \mathrm{C}$ and flow rate was $0.5 \mathrm{~mL} / \mathrm{min}$. Compounds were monitored in positive mode in single ion recording (SIR) mode and quantified used standard curves (see Table 2 for MS parameters). In all cases probe temperature was $500^{\circ} \mathrm{C}$ with a gain of 5 .

\section{Youden Trial for Determination of Major Factors Effecting Melatonin Stability}

Samples were prepared by diluting pure analytical melatonin standard in desired solvent to a concentration of $0.01 \mathrm{mg} / \mathrm{mL}$.

TABLE 2 | Mass spectrometer parameters for analysis in SIR mode.

\begin{tabular}{lllc}
\hline Analyte & $\mathbf{m} / \mathbf{z}$ & lonization mode & Cone voltage \\
\hline Serotonin & 177 & ESI+ & 10 \\
Tryptophan & 205 & ESI+ & 10 \\
Tryptamine & 144 & ESI+ & 15 \\
N-acetylserotonin & 257 & ESI+ & 5 \\
Melatonin & 233 & ESI+ & 15
\end{tabular}

ESI-electrospray ionization; $m / z$-mass to charge ratio.
Sample were then exposed to levels according to runs designated in Table 3, following a fractional factorial Youden design (Karageorgou and Samanidou, 2014). Factors tested were temperature $\left(4\right.$ or $\left.40^{\circ} \mathrm{C}\right)$, sonication $(0$ or $30 \mathrm{~min})$, light (dim green or white), oxidation (bubble through with nitrogen gas $10 \mathrm{~s}$, or not), and solvent (10 or $100 \%$ methanol; $\mathrm{MeOH}$ ). For example, in run one, all samples would be made up in $100 \% \mathrm{MeOH}$, prepared under dim green light (green) at $4^{\circ} \mathrm{C}$, would be bubbled through with nitrogen gas then left to sit for $30 \mathrm{~min}$ without sonication. Organic solvent utilized was pure analytical grade $\mathrm{MeOH}$ (Fisher Scientific, Canada) diluted to 10 or $100 \%$ with ultra-pure water. For sonication samples not undergoing sonication were held under controlled conditions for an equivalent amount of time without sonication. All runs were conducted using either an ice both or a heated temperature controlled water bath. All runs were repeated in triplicate and conducted one at a time to ensure all samples underwent the same duration of extraction (approximately $40 \mathrm{~min}$ ). Samples were diluted ten times before being injected $(1 \mu \mathrm{L})$ for analysis on a Waters Classic Acquity ultra performance liquid chromatography (UPLC) system with electrochemical detection (Coulochem III, ESA, Dionex, ThermoFisher Scientific; ECD) equipped with an ultra-analytical coulometric flow cell (ThermoFisher Scientific, USA). Separation was performed on a Waters BEH Phenyl column $(2.1 \times 50 \mathrm{~mm}, 1.7 \mu \mathrm{m})$ using an isocratic flow of $75 \% 100 \mathrm{mM}$ sodium acetate (Sigma Aldrich, Canada) buffer with $100 \mathrm{mM}$ citric acid (Sigma Aldrich, Canada), and $25 \% \mathrm{MeOH}$ at a rate of $0.4 \mathrm{~mL} / \mathrm{min}$ with a column temperature of $35^{\circ} \mathrm{C}$. Detection was performed with screening voltage of $100 \mathrm{mV}$, and detection at $850 \mathrm{mV}, 1 \mu \mathrm{A}$ collecting 30 points per second. Melatonin eluted at $3.5 \mathrm{~min}$, limit of detection was determined to be $10 \mathrm{ng} / \mathrm{mL}$ and limit of quantification was $30 \mathrm{ng} / \mathrm{mL}$. To calculate effect of the various factors the average percent melatonin concentration remaining in high treatments was subtracted from the average percent melatonin content remaining in the low treatment level. Melatonin standard was purchased from Sigma Aldrich, Canada.

\section{Media Stability}

Fifty millimolars Melatonin and serotonin stock solutions were prepared in 96\% ethanol (Philips Canada, Scarborough,

TABLE 3 | Design for Youden trial, in all cases $\boldsymbol{n}=3$, uppercase letter indicates high level, lowercase letters indicate low level.

\begin{tabular}{llllll}
\hline & $\begin{array}{l}\text { Temperature } \\
\text { (A/a) }\end{array}$ & $\begin{array}{l}\text { Sonication } \\
\text { (B/b) }\end{array}$ & $\begin{array}{l}\text { Light } \\
\text { (C/c) }\end{array}$ & $\begin{array}{l}\text { Oxidation } \\
\text { (D/d) }\end{array}$ & $\begin{array}{l}\text { Solvent } \\
\text { (E/e) }\end{array}$ \\
\hline Run 1 & $4^{\circ} \mathrm{C}(\mathrm{a})$ & $0 \mathrm{~min}(\mathrm{~b})$ & Green (c) & Nitrogen (d) & $100 \% \mathrm{MeOH}(\mathrm{e})$ \\
Run 2 & $40^{\circ} \mathrm{C}(\mathrm{A})$ & $0 \mathrm{~min}$ & Green & $-(\mathrm{D})$ & $10 \% \mathrm{MeOH}(\mathrm{E})$ \\
Run 3 & $4^{\circ} \mathrm{C}$ & $30 \mathrm{~min}(\mathrm{~B})$ & Green & - & $10 \% \mathrm{MeOH}$ \\
Run 4 & $40^{\circ} \mathrm{C}$ & $30 \mathrm{~min}$ & Green & Nitrogen & $100 \% \mathrm{MeOH}$ \\
Run 5 & $4^{\circ} \mathrm{C}$ & $0 \mathrm{~min}$ & White (C) & Nitrogen & $100 \% \mathrm{MeOH}$ \\
Run 6 & $40^{\circ} \mathrm{C}$ & $0 \mathrm{~min}$ & White & - & $10 \% \mathrm{MeOH}$ \\
Run 7 & $4^{\circ} \mathrm{C}$ & $30 \mathrm{~min}$ & White & - & $10 \% \mathrm{MeOH}$ \\
Run 8 & $40^{\circ} \mathrm{C}$ & $30 \mathrm{~min}$ & White & Nitrogen & $100 \% \mathrm{MeOH}$
\end{tabular}


Ontario), just prior to media sterilization and stored at $-20^{\circ} \mathrm{C}$ until ready for use. For media preparation three media salts were utilized: Murashige and Skoog, Driver and Kunyuki (DKW) and Llyod and McCown's woody plant medium (WPM) with Gamborg B5 vitamins as per the manufacturers recommended concentrations and media were further supplemented with $3 \%$ sucrose (Murashige and Skoog, 1962; Gamborg et al., 1968; McCown and Lloyd, 1981; Driver and Kuniyuki, 1984). Media pH was adjusted to 5.7 using $0.1 \mathrm{~N}$ sodium hydroxide (Fisher Scientific, Canada) and sterilized by autoclaving for $20 \mathrm{~min}$ at $121^{\circ} \mathrm{C}$ and 21 PSI. Post-autoclaving, media was cooled by incubating in a water bath at $55^{\circ} \mathrm{C}$. Melatonin and serotonin were then added to media in an aseptic fashion for a final concentration of $25 \mu \mathrm{M}$ each. Media were then dispensed into Magenta GA-7 boxes (Caisson Labs, Utah, USA) and further divided into light $\left(\sim 40 \mu \mathrm{mol} \mathrm{m} \mathrm{m}^{2}\right)$ and dark $\left(0 \mu \mathrm{mol} \mathrm{m} \mathrm{s}^{2}\right)$ treatments, each replicated thrice. All boxes were sealed with $3 \mathrm{M}$ Micropore tape and were stored in growth rooms maintained at $24 \pm 2{ }^{\circ} \mathrm{C}$ under a $16 \mathrm{~h}$ photoperiod provided by cool white fluorescent lamps (Philips Canada, Scarborough, ON). $500 \mu \mathrm{L}$ samples were collected aseptically at $0 \mathrm{~min}$ (immediately after addition of melatonin or serotonin stock to medium), $5 \mathrm{~min}$, $30 \mathrm{~min}, 1 \mathrm{~h}, 3 \mathrm{~h}, 6 \mathrm{~h}, 12 \mathrm{~h}, 24 \mathrm{~h}, 3$ days, 10 days, 14 days, 21 days, and 28 days, and flash frozen in liquid nitrogen and stored at $-80^{\circ} \mathrm{C}$.

To remove media salts and sugar from samples, samples were loaded onto a Waters Oasis HLB solid phase extraction (SPE) cartridge ( $1 \mathrm{cc}, 30 \mathrm{mg}$, Waters, Canada), samples were then washed with $1 \mathrm{~mL}$ of Milli-Q water and eluted in $0.5 \mathrm{~mL}$ of $100 \%$ MS grade $\mathrm{MeOH}$. Samples were then diluted ten times in Milli-Q water and $5 \mu \mathrm{L}$ was injected and analyzed following the validated UPLC-MS protocol as described above.

\section{Data Analysis}

All data were plotted and analyzed in Microsoft Excel 360 (Microsoft, USA) for experiments performed on the UPLC-ECD system, while all data from UPLC-MS experiments were plotted and analyzed in GraphPad Prism 6. For media analysis treatment groups were compared using a paired two-way ANOVA, with $\alpha=0.05$. The Youden trial was designed and analyzed as per the literature, with only five factors included (Karageorgou and Samanidou, 2014). All samples were repeated in triplicate, and all experiments were replicated twice, and data was combined.

\section{RESULTS}

The method presented in this paper showed good specificity for all compounds due to the use of a single quadrupole system in SIR mode (Figures 1, 2), with all peaks being completely resolved from surrounding peaks and showing good signal to noise $(>3: 1)$ in the linear range. Endogenous concentrations in all matrices are shown in Table 4.

Instrument limits of detection were $24.4 \mathrm{ng} / \mathrm{mL}, 6.1 \mathrm{ng} / \mathrm{mL}$, $1.52 \mathrm{ng} / \mathrm{mL}, \quad 6.1 \mathrm{ng} / \mathrm{mL}$, and $92.5 \mathrm{pg} / \mathrm{mL}$ for serotonin, tryptophan, tryptamine, NAS and melatonin, respectively. Method detection limits were found to be $1.62 \mu \mathrm{g} / \mathrm{g}, 0.407$ $\mu \mathrm{g} / \mathrm{g}, 0.101 \mu \mathrm{g} / \mathrm{g}, 0.407 \mu \mathrm{g} / \mathrm{g}$, and $6.17 \mathrm{ng} / \mathrm{g}$ respectively. The linear range (lower limit of quantification; LLOQ-upper limit of quantification; ULOQ) for each analyte was $97.7 \mathrm{ng} / \mathrm{mL}-25$ $\mu \mathrm{g} / \mathrm{mL}, 24.4 \mathrm{ng} / \mathrm{mL}-25 \mu \mathrm{g} / \mathrm{mL}, 6.1 \mathrm{ng} / \mathrm{mL}-6.25 \mu \mathrm{g} / \mathrm{mL}, 24.4$ $\mathrm{ng} / \mathrm{mL}-25 \mu \mathrm{g} / \mathrm{mL}$ and $38.1 \mathrm{pg} / \mathrm{mL}-6.25 \mu \mathrm{g} / \mathrm{mL}$ for serotonin, tryptophan, tryptamine, NAS, and melatonin respectively, showing a linear range of more than 4 orders of magnitude (Table 5).

Excellent reproducibility, presented as percent relative standard deviations (\% RSD), was demonstrated for all five analytes in all of the eight matrices ranging from $4-8$ and $1-9 \%$ in low and high spikes respectively for serotonin; $2-4$ and $4-5 \%$ for tryptophan; $2-7$ and $1-5 \%$ for tryptamine; $1-4 \%$ for both low and high spikes in $\mathrm{N}$-acetylserotonin and $7-8$ and $6-10 \%$ for melatonin (Table 6).

Recovery was also acceptable for all matrices and analytes with low concentration spike recoveries ranging from $85 \%$ in banana root to $110 \%$ in potato shoot for serotonin; $93 \%$ in SJW shoot to $101 \%$ in tobacco shoot for tryptophan; $90 \%$ in SJW root to $110 \%$ in Artemisia root for tryptamine; 93\% in Artemisia shoot to $110 \%$ in fennel seed for NAS and $94 \%$ in fennel seed to $113 \%$ in Artemisia root for melatonin. At high concentration recoveries were similar with values of $97-113 \%$ for serotonin (SJW root, and banana root); 94-101\% for tryptophan (SJW and Artemisia root); 82-104\% for tryptamine (SJW and Artemisia root); $90-101 \%$ for NAS (fennel seed and root); and $92-105 \%$ for melatonin (SJW shoot and Artemisia root) (Table 6).

Youden trials are factorial designs which are generally utilized to test the robustness of a method, and determine the level of variability which can exist in a particular method before the results are effected. As such two extreme values for likely conditions which a sample may be subjected to: a high and a low value are utilized and effects can then be measured (Karageorgou and Samanidou, 2014). In this case the Youden trial was run to investigate the stability of melatonin during the extraction protocol found that light, oxygen exposure (oxidation) and solvent concentration were not significant factors contributing to melatonin degradation. Temperature had a significant impact on melatonin concentration remaining in samples, while sonication had a nominal effect (Figure 3).

Investigation of the stability of melatonin and serotonin found that compounds remained relatively stable across the first 10 days in media with values declining up to a $10 \%$ loss for melatonin at day 28 and losses of up to $40 \%$ at $28 \mathrm{~d}$ for serotonin. There was no significant difference in the trends observed for any of the three media types: WPM, DKW, and Murashige and Skoog and no difference between culture boxes stored in the light or in complete darkness of the $28 \mathrm{~d}$ period (Figure 4).

\section{DISCUSSION}

Melatonin is increasingly being recognized as an important regulator of plant growth, development and adaptation (Erland et al., 2015). As such there is a rapidly growing body of knowledge examining the roles melatonin plays in plants, many of which employ controlled environment systems and in particular in vitro culture systems, many of which are helping to solidify the 


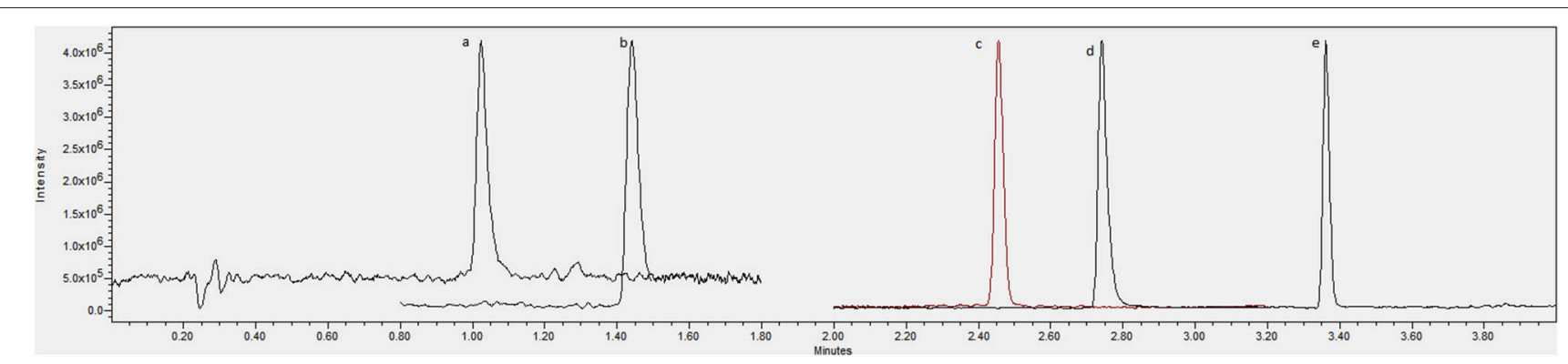

FIGURE 1 | Chromatogram showing an overlay of channels for (A) serotonin, (B) tryptophan, (C) tryptamine, (D) N-acetylserotonin and (E) melatonin standards at $1 \mu \mathrm{g} / \mathrm{mL}$.
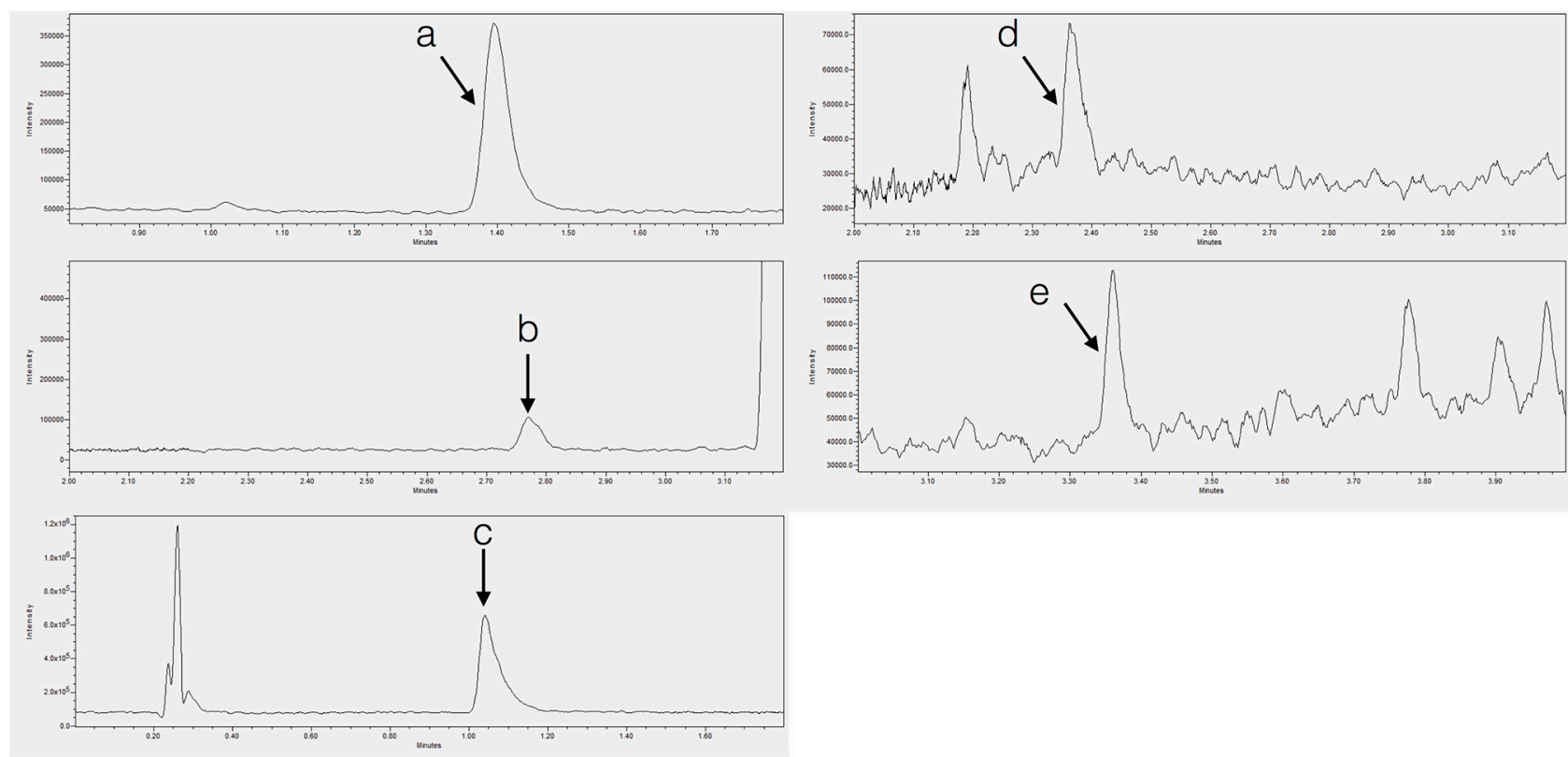

FIGURE 2 | Chromatograms showing endogenous (A) tryptophan in tobacco shoot, (B) tryptamine in tobacco shoot, (C) serotonin in banana root, (D) $\mathrm{N}$-acetylserotonin in potato shoot, and (E) melatonin in SJW shoot.

role of melatonin in plant processes. As both the receptors and mechanisms underlying the functions of melatonin in plants while an active area of research are still poorly understood, in vitro systems offer a valuable platform for their investigation (Lee and Back, 2016; Sanchez-Barcelo et al., 2016; Shi et al., 2016; Wei et al., 2016). One such important strategy, which has helped to confirm for example the importance of calcium signaling in melatonin responses in several species, is the inclusion of inhibitors in plant medium (Murch et al., 2001; Jones et al., 2007; Ramakrishna et al., 2009, 2011). The in vitro culture system also offers a unique opportunity compared to greenhouse and field trials, in that treatment conditions can be closely monitored and allow for treatment of many plants, and all cultures are maintained in aseptic conditions. This of particular value with respect to the indoleamines, due to their ubiquitous production across kingdoms, therefore any microbial contamination could confound important results.
As the interest in melatonin continues to rise, many labs require not only practical and effective platforms via which to study the physiological effects of melatonin but also assays by which to determine the actual quantities of melatonin in a particular sample. Though melatonin has now been examined in many systems, including in culture, there still remains inconsistency in the literature as to the quantities of melatonin in individual plants and the methods by which to extract it. This is well illustrated in Table $\mathbf{1}$ which summarizes some of the many extraction protocols which have been utilized. Times to complete extraction range from $<15 \mathrm{~min}$ to over $16 \mathrm{~h}$, and in most cases specific times to complete the entire extraction process are not specifically mentioned, with the reader left to presume extraction times based on the time for individual steps such as shaking, sonication or drying. The relevance of this inconsistency in extraction conditions, is also reflected in several reports on the stability of melatonin. Though several reports 
TABLE 4 | Concentrations of tryptophan (Trp), tryptamine (Trm), serotonin (Ser), N-acetylserotonin (NAS) and melatonin (Mel) in tissues studied in this validation.

\begin{tabular}{|c|c|c|c|c|c|c|}
\hline \multirow[t]{2}{*}{ Species } & \multirow[t]{2}{*}{ Tissue } & \multicolumn{5}{|c|}{ Mean concentration in tissue (standard error) } \\
\hline & & $\operatorname{Trp}(\mu \mathrm{g} / \mathrm{gFW})$ & $\operatorname{Trm}(\mu \mathrm{g} / \mathrm{g} \mathrm{FW})$ & Ser $(\mu \mathbf{g} / \mathbf{g ~ F W})$ & NAS (ng/g FW) & Mel (ng/g FW) \\
\hline \multirow[t]{2}{*}{ SJW } & Shoot & $164.8(25.4)$ & $1.51(0.31)$ & nd & nd & $32.5(1.70)$ \\
\hline & Root & $15.2(2.8)$ & $0.599(0.057)$ & nd & nd & $9.72(1.12)$ \\
\hline African violet & Shoot & $58.9(18.2)$ & $0.508(0.085)$ & nd & nd & nd \\
\hline \multirow[t]{2}{*}{ Banana } & Shoot & $91.2(12.3)$ & $0.627(0.063)$ & $7.17(1.68)$ & nd & $16.81(2.2)$ \\
\hline & Root & $20.2(5.0)$ & $0.486(0.008)$ & 34.17 (6.36) & nd & nd \\
\hline Elm & Shoot & $16.7(1.7)$ & nd & nd & nd & nd \\
\hline \multirow[t]{2}{*}{ Tobacco } & Shoot & $16.3(2.2)$ & 0.721 (0.069) & nd & nd & nd \\
\hline & Root & $4.5(1.9)$ & nd & nd & 77.1 (9.9) & nd \\
\hline Potato & Shoot & 39.1 (5.3) & $0.719(0.17)$ & nd & 330 (86.4) & 40.05 (1.85) \\
\hline \multirow[t]{2}{*}{ Artemisia } & Shoot & $29.9(5.9)$ & nd & nd & nd & nd \\
\hline & Root & $15.1(1.1)$ & nd & nd & nd & nd \\
\hline Fennel & Seed & $24.43(2.73)$ & 0.0733 (0.0126) & nd & nd & 33.30 (13.0) \\
\hline
\end{tabular}

TABLE 5 | Summary of retention time, and instrument and method limits of detection and quantification for all analytes investigated.

\begin{tabular}{|c|c|c|c|c|c|c|c|}
\hline Analyte & $\begin{array}{l}\text { Retention } \\
\text { time (min) }\end{array}$ & $\begin{array}{l}\text { Instrument } \\
\text { LOD (ng/mL) }\end{array}$ & $\begin{array}{c}\text { Method } \\
\text { LOD }(\mu \mathrm{g} / \mathrm{g})\end{array}$ & $\begin{array}{c}\text { Instrument } \\
\text { LLOQ (ng/mL) }\end{array}$ & $\begin{array}{c}\text { Method } \\
\text { LLOQ }(\mu \mathrm{g} / \mathrm{g})\end{array}$ & $\begin{array}{c}\text { Instrument } \\
\text { ULOQ }(\mu \mathrm{g} / \mathrm{mL})\end{array}$ & $\begin{array}{c}\text { Method } \\
\text { ULOQ (mg/g) }\end{array}$ \\
\hline Serotonin & 1.057 & 24.4 & 1.62 & 97.7 & 6.51 & 25 & 1.67 \\
\hline Tryptophan & 1.045 & 6.10 & 0.407 & 24.4 & 1.62 & 25 & 1.67 \\
\hline Tryptamine & 2.752 & 1.52 & 0.101 & 6.1 & 0.407 & 6.25 & 0.42 \\
\hline $\mathrm{N}$-acetylserotonin & 2.480 & 6.10 & 0.407 & 24.4 & 1.62 & 25 & 1.67 \\
\hline Melatonin & 3.369 & 0.093 & 0.00617 & 0.38 & 0.0254 & 6.25 & 0.42 \\
\hline
\end{tabular}

LOD-limit of detection, LLOQ-lower limit of quantification, RT-retention time, ULOQ-upper limit of quantification.

have found melatonin to be stable in aqueous solution over long periods of time regardless of $\mathrm{pH}$ (e.g., 5-12) and storage temperatures (e.g., 4 vs. $-70^{\circ} \mathrm{C}$ ), still others have suggested that melatonin may undergo degradation under particular conditions such as light exposure (Cavallo and Hassan, 1995; Daya et al., 2001; Maharaj and Dukie, 2002). The majority of these studies have, as noted, been performed in aqueous solution and with a view toward mammalian systems. As plant systems have highly complex phytochemical environments, this level of complexity may suggest that further investigation is required specifically addressing the unique challenges presented by the plant system. Though the issue of the presence of melatonin isomers in plants has been raised by several reports (Tan et al., 2012), and represents an important field of study, the total melatonin content, or the sum of all melatonin isomers present in a sample, is the most commonly reported value across studies, and represents sufficient information for many basic plant physiological studies. Additionally, by considering only the total content, this allows for many more labs, beyond those with the specialized equipment and analytical background required for isomer determination, to investigate melatonin content in plants.

In view of these inconsistencies, this study presents two noteworthy achievements. First it presents a simple, accessible and easy to implement protocol for the analysis of not just melatonin or serotonin in plant tissues, but also their three precursors: tryptophan, tryptamine, and NAS, and secondly it presents an in-depth investigation of the levels of melatonin and serotonin which persist in plant tissue culture medium under variable lighting conditions and with varying media composition.

Despite previously published literature suggesting that light is a major factor leading to the degradation of melatonin, this study found that heat and to a lesser extent sonication had the greatest effect on the stability of melatonin, as sonication produces heat, even when sonication is performed in an ice bath, these two factors are interrelated emphasizing the impact of temperature on the stability of melatonin (Figure 3) (Maharaj and Dukie, 2002).

The method provided in this report is robust, reproducible and relatively simple, eliminating many factors which provide opportunities for loss of analyte, which is of particular importance, given concerns about the stability of melatonin in previous reports. Additionally, as interest in the mechanism behind melatonin's action in plants continues to grow, there is a need for easy to implement methods which provide reproducible results for not just melatonin, but its biosynthetic precursors as well. Accurate quantification of these compounds will allow for more in-depth studies into this important phytochemical signaling molecule.

This study has employed this method to address a significant question in melatonin investigations in plants. There are now 
TABLE 6 | Recovery data for serotonin, tryptophan, tryptamine, $\mathrm{N}$-acetylserotonin and melatonin.

\begin{tabular}{|c|c|c|c|c|c|}
\hline Species & Tissue & $\begin{array}{c}\text { Low } \\
\text { Recovery }^{\mathrm{a}} \\
\text { Average }\end{array}$ & $\begin{array}{c}\text { Low } \\
\text { Recovery }{ }^{a} \\
\text { \%RSD }\end{array}$ & $\begin{array}{c}\text { High } \\
\text { Recovery }^{\text {b }} \\
\text { Average }\end{array}$ & $\begin{array}{c}\text { High } \\
\text { Recovery }^{b} \\
\text { \%RSD }\end{array}$ \\
\hline \multicolumn{6}{|l|}{ SEROTONIN } \\
\hline SJW & Shoot & $103 \%$ & $5 \%$ & $100 \%$ & $1 \%$ \\
\hline SJW & Root & $101 \%$ & $6 \%$ & $97 \%$ & $2 \%$ \\
\hline African Violet & Shoot & $101 \%$ & $5 \%$ & $100 \%$ & $3 \%$ \\
\hline Banana & Shoot & $102 \%$ & $7 \%$ & $111 \%$ & $8 \%$ \\
\hline Banana & Root & $85 \%$ & $8 \%$ & $113 \%$ & $9 \%$ \\
\hline Elm & Shoot & $100 \%$ & $7 \%$ & $102 \%$ & $5 \%$ \\
\hline Tobacco & Shoot & $100 \%$ & $7 \%$ & $98 \%$ & $1 \%$ \\
\hline Tobacco & Root & $100 \%$ & $5 \%$ & $101 \%$ & $1 \%$ \\
\hline Potato & Shoot & $110 \%$ & $5 \%$ & $116 \%$ & $2 \%$ \\
\hline Artemisia & Shoot & $104 \%$ & $5 \%$ & $107 \%$ & $1 \%$ \\
\hline Artemisia & Root & $107 \%$ & $4 \%$ & $106 \%$ & $1 \%$ \\
\hline Fennel & Seed & $101 \%$ & $1 \%$ & $101 \%$ & $1 \%$ \\
\hline \multicolumn{6}{|c|}{ TRYPTOPHAN } \\
\hline SJW & Shoot & $93 \%$ & $3 \%$ & $98 \%$ & $5 \%$ \\
\hline SJW & Root & $94 \%$ & $3 \%$ & $94 \%$ & $5 \%$ \\
\hline African Violet & Shoot & $93 \%$ & $4 \%$ & $96 \%$ & $5 \%$ \\
\hline Banana & Shoot & $90 \%$ & $4 \%$ & $97 \%$ & $5 \%$ \\
\hline Banana & Root & $95 \%$ & $4 \%$ & $96 \%$ & $5 \%$ \\
\hline Elm & Shoot & $94 \%$ & $2 \%$ & $96 \%$ & $5 \%$ \\
\hline Tobacco & Shoot & $101 \%$ & $5 \%$ & $97 \%$ & $5 \%$ \\
\hline Tobacco & Root & $96 \%$ & $3 \%$ & $95 \%$ & $5 \%$ \\
\hline Potato & Shoot & $97 \%$ & $2 \%$ & $100 \%$ & $4 \%$ \\
\hline Artemisia & Shoot & $96 \%$ & $2 \%$ & $98 \%$ & $4 \%$ \\
\hline Artemisia & Root & $99 \%$ & $2 \%$ & $101 \%$ & $4 \%$ \\
\hline Fennel & Seed & $99 \%$ & $2 \%$ & $102 \%$ & $2 \%$ \\
\hline \multicolumn{6}{|c|}{ TRYPTAMINE } \\
\hline SJW & Shoot & $99 \%$ & $2 \%$ & $101 \%$ & $2 \%$ \\
\hline SJW & Root & $90 \%$ & $3 \%$ & $98 \%$ & $1 \%$ \\
\hline African Violet & Shoot & $92 \%$ & $2 \%$ & $96 \%$ & $1 \%$ \\
\hline Banana & Shoot & $94 \%$ & $2 \%$ & $94 \%$ & $2 \%$ \\
\hline Banana & Root & $106 \%$ & $7 \%$ & $100 \%$ & $2 \%$ \\
\hline Elm & Shoot & $92 \%$ & $3 \%$ & $103 \%$ & $2 \%$ \\
\hline Tobacco & Shoot & $98 \%$ & $3 \%$ & $104 \%$ & $2 \%$ \\
\hline Tobacco & Root & $98 \%$ & $5 \%$ & $104 \%$ & $2 \%$ \\
\hline Potato & Shoot & $106 \%$ & $2 \%$ & $105 \%$ & $2 \%$ \\
\hline Artemisia & Shoot & $86 \%$ & $7 \%$ & $82 \%$ & $5 \%$ \\
\hline Artemisia & Root & $110 \%$ & $7 \%$ & $104 \%$ & $2 \%$ \\
\hline Fennel & Seed & $110 \%$ & $3 \%$ & $99 \%$ & $2 \%$ \\
\hline \multicolumn{6}{|c|}{ N-ACETYLSEROTONIN } \\
\hline SJW & Shoot & $97 \%$ & $4 \%$ & $96 \%$ & $3 \%$ \\
\hline SJW & Root & $97 \%$ & $1 \%$ & $99 \%$ & $2 \%$ \\
\hline African Violet & Shoot & $100 \%$ & $1 \%$ & $95 \%$ & $1 \%$ \\
\hline Banana & Shoot & $104 \%$ & $2 \%$ & $98 \%$ & $1 \%$ \\
\hline Banana & Root & $104 \%$ & $2 \%$ & $99 \%$ & $2 \%$ \\
\hline Elm & Shoot & $99 \%$ & $1 \%$ & $100 \%$ & $2 \%$ \\
\hline Tobacco & Shoot & $99 \%$ & $2 \%$ & $97 \%$ & $3 \%$ \\
\hline Tobacco & Root & $102 \%$ & $2 \%$ & $99 \%$ & $2 \%$ \\
\hline
\end{tabular}

(Continued)
TABLE 6 | Continued

\begin{tabular}{|c|c|c|c|c|c|}
\hline Species & Tissue & $\begin{array}{c}\text { Low } \\
\text { Recovery } \\
\text { Average }\end{array}$ & $\begin{array}{c}\text { Low } \\
\text { Recovery } \\
\text { \%RSD }\end{array}$ & $\begin{array}{c}\text { High } \\
\text { Recovery }^{\mathbf{b}} \\
\text { Average }\end{array}$ & $\begin{array}{c}\text { High } \\
\text { Recovery }^{\text {b }} \\
\text { \%RSD }\end{array}$ \\
\hline Potato & Shoot & $98 \%$ & $1 \%$ & $97 \%$ & $2 \%$ \\
\hline Artemisia & Shoot & $93 \%$ & $2 \%$ & $94 \%$ & $1 \%$ \\
\hline Artemisia & Root & $95 \%$ & $3 \%$ & $101 \%$ & $4 \%$ \\
\hline Fennel & Seed & $110 \%$ & $3 \%$ & $90 \%$ & $2 \%$ \\
\hline \multicolumn{6}{|l|}{ MELATONIN } \\
\hline SJW & Shoot & $96 \%$ & $7 \%$ & $92 \%$ & $6 \%$ \\
\hline SJW & Root & $100 \%$ & $8 \%$ & $95 \%$ & $6 \%$ \\
\hline African Violet & Shoot & $98 \%$ & $7 \%$ & $96 \%$ & $6 \%$ \\
\hline Banana & Shoot & $98 \%$ & $7 \%$ & $97 \%$ & $6 \%$ \\
\hline Banana & Root & $106 \%$ & $8 \%$ & $97 \%$ & $6 \%$ \\
\hline Elm & Shoot & $99 \%$ & $7 \%$ & $98 \%$ & $6 \%$ \\
\hline Tobacco & Shoot & $101 \%$ & $7 \%$ & $98 \%$ & $7 \%$ \\
\hline Tobacco & Root & $104 \%$ & $7 \%$ & $89 \%$ & $10 \%$ \\
\hline Potato & Shoot & $106 \%$ & $7 \%$ & $100 \%$ & $7 \%$ \\
\hline Artemisia & Shoot & $102 \%$ & $7 \%$ & $98 \%$ & $7 \%$ \\
\hline Artemisia & Root & $113 \%$ & $8 \%$ & $105 \%$ & $6 \%$ \\
\hline Fennel & Seed & $94 \%$ & $1 \%$ & $98 \%$ & $5 \%$ \\
\hline
\end{tabular}

alow spike concentration was $0.5 \mu \mathrm{g} / \mathrm{mL}$.

${ }^{b}$ high spike concentration was $5 \mu \mathrm{g} / \mathrm{mL}$.

many reports on the role melatonin plays in plant development, reproduction and survival of biotic and abiotic stresses (Erland et al., 2015; Reiter et al., 2015; Hardeland, 2016). Many investigations employ treatment of plants with melatonin in a liquid dose, or in systems such as plant tissue culture in liquid or solid medium. In particular, in vitro culture experiments involve the storage of plants under light conditions and relatively warm temperatures for extended periods of time with data collection often happening after days or weeks. The actual levels of melatonin or serotonin in this medium, however, have never been determined. Due to previous reports of the instability of melatonin under light and a negative effect of temperature as reported in this manuscript, a study was undertaken to investigate the actual exposure concentrations for melatonin in in vitro culture systems. This is particularly salient as significant or immediate decreases in indoleamine content could lead to much lower exposure concentrations than are reported and present an artificially inflated active concentration. Surprisingly, both serotonin and melatonin were found to be stable in three common media types tested for 10 days of culture. This time-frame is important as developmental patterns are often established early-on in in vitro cultured plants and tissues. Many experiments, however, use 21 and 28 days as convenient points for data collection as plant organs are generally sufficiently developed by this time to allow for accurate measurement. It was therefore important to determine if the concentrations in medium are sustained over the entire experiment. Though variability is present in media data, possibly due to box to box differential degradation across culture vessels, and variability introduced during sample collection, these fluctuations do not significantly change the observed trend. Serotonin showed up to 


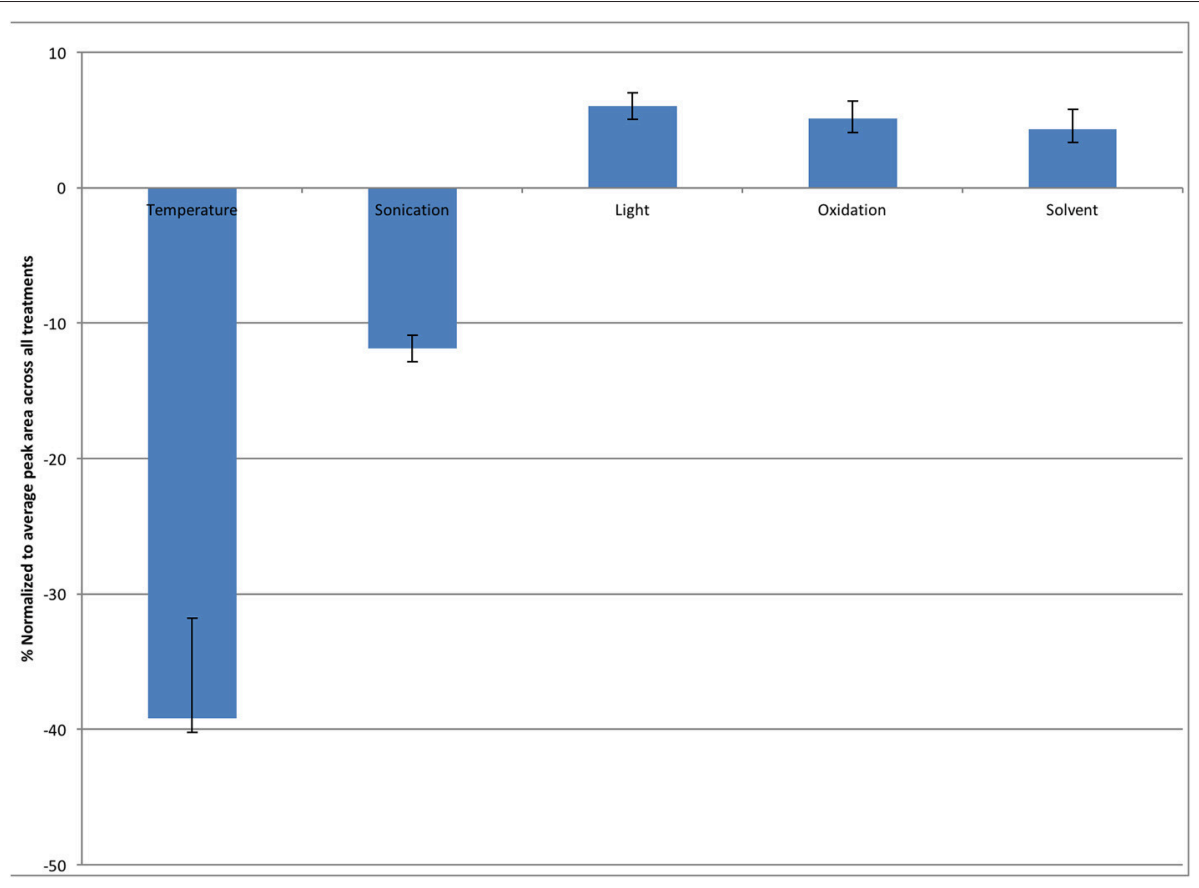

FIGURE 3 | Effect of varying extraction conditions on the stability of melatonin in solution, expressed as the difference between amount remaining at the high and low levels of factors. Error bars represent standard error, $n=3$.
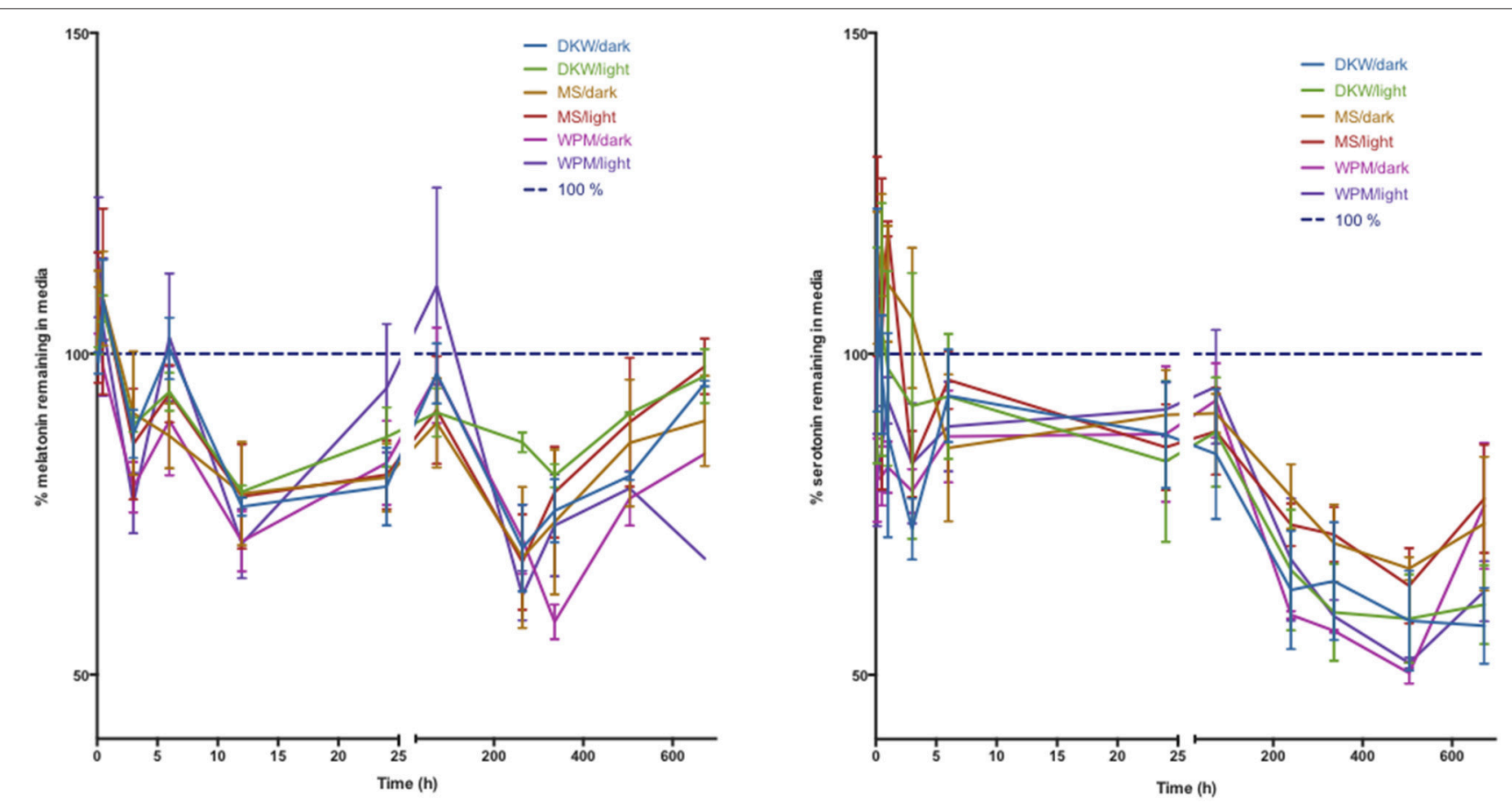

FIGURE 4 | Stability of melatonin (left) and serotonin (right) in three types of plant tissue culture medium. DKW-Driver Kuniyuki walnut; MS-Murashige and Skoog; WPM - woody plant medium. Dark indicates $24 \mathrm{~h}$ darkness, light indicates a $16 \mathrm{~h}$ photoperiod. Initial media concentration of melatonin and serotonin was $25 \mu \mathrm{M}$. 
a $40 \%$ loss in concentration after 28 days, surprisingly, melatonin only showed a $10 \%$ decrease in concentration.

Many plant growth experiments use different growth medium compositions varying sources of nitrogen, iron, and other important nutrients to support robust and normal plant growth. It was hypothesized that these different macro- and micronutrient compositions may have an effect on stability, if losses were due to a chemical interaction with media constituents (Murashige and Skoog, 1962; McCown and Lloyd, 1981; Driver and Kuniyuki, 1984). The results shown in Figure 2, however, show that there was not any difference in the degradation trend between three commonly used media types. Furthermore, it was theorized that light exposure would have a significant impact on media concentrations of melatonin and serotonin. Again, however, it was found that light levels ( $16 \mathrm{~h}$ photoperiod vs. complete dark) had no significant effect on concentrations, suggesting that photooxidation or photo-degradation is not a significant factor in the design of experiments. This is particularly important as many reports have utilized diverse culture vessels ranging from clear glass test tubes to black plastic pots and employ different lighting conditions ranging from ambient light in a greenhouse to strictly controlled light spectra (Erland et al., 2015). These results eliminate vessel color, wavelength or light conditions as an important variable in these experiments and provide further confidence moving forwards.

The data presented in this study are relevant as they address an important but previously un-investigated variable in the design of plant physiology experiments in plant culture systems. Additionally, they validate many previous studies which have been published investigating the important roles of melatonin across diverse plant species and in response to changing conditions (Erland et al., 2015; Reiter et al., 2015; Hardeland, 2016).

\section{REFERENCES}

Afreen, F., Zobayed, S. M. A., and Kozai, T. (2006). Melatonin in Glycyrrhiza uralensis: response of plant roots to spectral quality of light and UV-B radiation. J. Pineal Res. 41, 108-115. doi: 10.1111/j.1600-079X.2006.00337.x

AOAC International (2013). "Appendix K: guidelines for dietary supplements and botanicals," in Official Methods of Analysis, ed M. D. Gaithersburg (Arlington, TX: AOAC), 1-32.

Arnao, M. B., and Hernández-Ruiz, J. (2007). Melatonin promotes adventitiousand lateral root regeneration in etiolated hypocotyls of Lupinus albus L. J. Pineal Res. 42, 147-152. doi: 10.1111/j.1600-079X.2006.00396.x

Arnao, M. B., and Hernández-Ruiz, J. (2009). Protective effect of melatonin against chlorophyll degradation during the senescence of barley leaves. J. Pineal Res. 46, 58-63. doi: 10.1111/j.1600-079X.2008.00625.x

Arnao, M. B., and Hernández-Ruiz, J. (2013). Growth conditions influence the melatonin content of tomato plants. Food Chem. 138, 1212-1214. doi: 10.1016/j.foodchem.2012.10.077

Betz, J. M., Brown, P. N., and Roman, M. C. (2011). Accuracy, precision, and reliability of chemical measurements in natural products research. Fitoterapia 82, 44-52. doi: 10.1016/j.fitote.2010.09.011

Bliesner, D. M. (2005). Validating Chromatographic Methods: A Practical Guide. Hoboken, NJ: John Wiley and Sons Inc.

Byeon, Y., and Back, K. (2014). An increase in melatonin in transgenic rice causes pleiotropic phenotypes, including enhanced seedling growth, delayed flowering, and low grain yield. J. Pineal Res. 56, 408-414. doi: 10.1111/jpi.12129
In summary, a validated method which allows for accurate, sensitive, and reproducible quantification of melatonin, and its biosynthetic precursors: serotonin, tryptophan, NAS, and tryptamine, was determined. This method was found to be robust in the analysis of these compounds across diverse plant species and tissue types. Additionally, measurement of melatonin and serotonin via this method in plant tissue culture medium found that neither light nor media composition had an effect on stability of melatonin or serotonin in these systems. Both melatonin and serotonin were found to be stable in medium across 10 days and losses after 28 days only reached 10 and $40 \%$ of the initial concentration respectively. These results pave the way for future in depth experiments examining the roles of melatonin and its precursors in both basic scientific investigations of plant physiological processes, and industrial applications such as micropropagation and cryo-banking.

\section{AUTHOR CONTRIBUTIONS}

All authors (LE, AC, AJ, and PS) participated in experimental design, manuscript preparation and agree to be accountable for all aspects of the work and provided final approval of the version to be published; LE conducted experiments and performed data analysis; AC assisted in conducting experiments; PS was responsible for study conception; LE, PS, and AJ participated in interpretation of data.

\section{FUNDING}

This research was supported by grants from the Gosling Foundation through the Gosling Institute for Plant Preservation and the National Sciences and Engineering Research Council (NSERC) [grant number 46741] of Canada.
Byeon, Y., Yool Lee, H., Choi, D.-W., and Back, K. (2014). Chloroplastencoded serotonin $\mathrm{N}$-acetyltransferase in the red alga Pyropia yezoensis: gene transition to the nucleus from chloroplasts. J. Exp. Bot. 66, 709-717. doi: $10.1093 / \mathrm{jxb} / \mathrm{eru} 357$

Cao, J., Murch, S. J., O’Brien, R., and Saxena, P. K. (2006). Rapid method for accurate analysis of melatonin, serotonin and auxin in plant samples using liquid chromatography-tandem mass spectrometry. J. Chromatog. A 1134, 333-337. doi: 10.1016/j.chroma.2006.09.079

Cavallo, A., and Hassan, M. (1995). Stability of melatonin in aqueous solution. J. Pineal Res. 18, 90-92. doi: 10.1111/j.1600-079X.1995.tb00145.x

Daya, S., Walker, R. B., Glass, B. D., and Anoopkumar-Dukie, S. (2001). The effect of variations in $\mathrm{pH}$ and temperature on stability of melatonin in aqueous solution. J. Pineal Res. 31, 155-158. doi: 10.1034/j.1600-079x.2001.31 0209.x

Driver, J. A., and Kuniyuki, A. H. (1984). In vitro propagation of Paradox walnut rootstock [Juglans hindsii X Juglans regia, tissue culture]. Hortic. Sci. 19, 507-509.

Dubbels, R., Reiter, R. J., Klenke, E., Goebel, A., Schnakenberg, E., Ehlers, C., et al. (1995). Melatonin in edible plants identified by radioimmunoassay and by high performance liquid chromatography-mass spectrometry. J. Pineal Res. 18, 28-31. doi: 10.1111/j.1600-079X.1995.tb00136.x

Erland, L. A., Murch, S. J., Reiter, R. J., and Saxena, P. K. (2015). A new balancing act: the many roles of melatonin and serotonin in plant growth and development. Plant Signal. Behav. 10:e1096469. doi: 10.1080/15592324.2015.1096469 
Gamborg, O. L., Miller, R. A., and Ojima, K. (1968). Nutrient requirements of suspension cultures of soybean root cells. Exp. Cell Res. 50, 151-158. doi: 10.1016/0014-4827(68)90403-5

Garcia-Parrilla, M. C., Cantos, E., and Troncoso, A. M. (2009). Analysis of melatonin in foods. J. Food Comp. Anal. 22, 177-183. doi: 10.1016/j.jfca.2008. 09.009

Gardana, C., Iriti, M., Stuknyte, M., De Noni, I., and Simonetti, P. (2014). "Melatonin isomer" in wine is not an isomer of the melatonin but tryptophanethylester. J. Pineal Res. 57, 435-441. doi: 10.1111/jpi.12183

Gomez, F. J. V., Hernández, I. G., Martinez, L. D., Silva, M. F., and Cerutti, S. (2013). Analytical tools for elucidating the biological role of melatonin in plants by LC-MS/MS. Electrophoresis 34, 1749-1756. doi: 10.1002/elps.201200569

Gomez, F. J. V., Raba, J., Cerutti, S., and Silva, M. F. (2012). Monitoring melatonin and its isomer in Vitis vinifera cv. Malbec by UHPLC-MS/MS from grape to bottle. J. Pineal Res. 52, 349-355. doi: 10.1111/j.1600-079X.2011.00949.x

Hardeland, R. (2016). Melatonin in plants - diversity of levels and multiplicity of functions. Front. Plant Sci. 7:198. doi: 10.3389/fpls.2016.00198

Hattori, A., Migitaka, H., Iigo, M., Itoh, M., Yamamoto, K., Ohtani-Kaneko, R., et al. (1995). Identification of melatonin in plants and its effects on plasma melatonin levels and binding to melatonin receptors in vertebrates. Biochem. Mol. Biol. Int. 35, 627-634.

Hernández, I. G., Gomez, F. J. V., Cerutti, S., Arana, M. V., and Silva, M. F. (2015). Melatonin in Arabidopsis thaliana acts as plant growth regulator at low concentrations and preserves seed viability at high concentrations. Plant Physiol. Biochem. 94, 191-196. doi: 10.1016/j.plaphy.2015.06.011

Huang, X., and Mazza, G. (2011). Application of LC and LC-MS to the analysis of melatonin and serotonin in edible plants. Crit. Rev. Food Sci. Nutr. 51, 269-284. doi: 10.1080/10408398.2010.529193

Iriti, M., and Vigentini, I. (2015). Tryptophan-ethylester, the false (unveiled) melatonin isomer in red wine. Int. J. Tryptophan Res. 8, 27-29. doi: 10.4137/IJTR.S22450

Jiao, J., Ma, Y., Chen, S., Liu, C., Song, Y., Qin, Y., et al. (2016). Melatoninproducing endophytic bacteria from grapevine roots promote the abiotic stressInduced production of endogenous melatonin in their hosts. Front. Plant Sci. 7:542. doi: 10.3389/fpls.2016.01387

Jones, M. P. A., Cao, J., O’Brien, R., Murch, S. J., and Saxena, P. K. (2007). The mode of action of thidiazuron: auxins, indoleamines, and ion channels in the regeneration of Echinacea purpurea L. Plant Cell Rep. 26, 1481-1490. doi: 10.1007/s00299-007-0357-0

Kang, K., Lee, K., Park, S., Kim, Y.-S., and Back, K. (2010). Enhanced production of melatonin by ectopic overexpression of human serotonin $\mathrm{N}$-acetyltransferase plays a role in cold resistance in transgenic rice seedlings. J. Pineal Res. 49, 176-182. doi: 10.1111/j.1600-079x.2010.00783.x

Karageorgou, E., and Samanidou, V. (2014). Youden test application in robustness assays during method validation. J. Chromatogr. A 1353, 131-139. doi: 10.1016/j.chroma.2014.01.050

Kocadağlı, T., Yılmaz, C., and Gökmen, V. (2014). Determination of melatonin and its isomer in foods by liquid chromatography tandem mass spectrometry. Food Chem. 153, 151-156. doi: 10.1016/j.foodchem.2013.12.036

Lazár, D., Murch, S. J., Beilby, M. J., and Khazaaly, A.l, S. (2013). Exogenous melatonin affects photosynthesis in characeae Chara australis. Plant Signal. Behav. 8:e23279. doi: 10.4161/psb.23279

Lee, H. Y., and Back, K. (2016). Mitogen-activated protein kinase pathways are required for melatonin-mediated defense responses in plants. J. Pineal Res. 60, 327-335. doi: 10.1111/jpi.12314

Maharaj, D. S., and Dukie, S. A. (2002). The identification of the UV degradants of melatonin and their ability to scavenge free radicals. J. Pineal Res. 32, 257-261. doi: 10.1034/j.1600-079X.2002.01866.X

Manchester, L. C., Tan, D. X., Reiter, R. J., Park, W., and Monis, K. (2000). High levels of melatonin in the seeds of edible plants: possible function in germ tissue protection. Life Sci. 25, 3023-3029. doi: 10.1016/S0024-3205(00)00896-1

McCown, B. H., and Lloyd, G. (1981). Woody plant medium (WPM). A mineral nutrient formulation for microculture of wood plant species. Hortic. Sci. 16, 453-459.

Mukherjee, S., David, A., Yadav, S., Baluška, F., and Bhatla, S. C. (2014). Salt stressinduced seedling growth inhibition coincides with differential distribution of serotonin and melatonin in sunflower seedling roots and cotyledons. Physiol. Plant. 152, 714-728. doi: 10.1111/ppl.12218
Murashige, T., and Skoog, F. (1962). A revised medium for rapid growth and bioassays with tobacco tissue cultures. Physiol. Plant. 15, 473-497. doi: 10.1111/j.1399-3054.1962.tb08052.x

Murch, S. J., Alan, A. R., Cao, J., and Saxena, P. K. (2009). Melatonin and serotonin in flowers and fruits of Datura metel L. J. Pineal Res. 47, 277-283. doi: 10.1111/j.1600-079X.2009.00711.x

Murch, S. J., Campbell, S. S. B., and Saxena, P. K. (2001). The role of serotonin and melatonin in plant morphogenesis: regulation of auxin-induced root organogenesis in in vitro-cultured explants of St. John's Wort (Hypericum perforatum L.). In Vitro Cell Devl. Biol. Plant 37, 786-793. doi: 10.1007/s11627001-0130-y

Murch, S. J., Hall, B. A., Le, C. H., and Saxena, P. K. (2010). Changes in the levels of indoleamine phytochemicals during véraison and ripening of wine grapes. J. Pineal Res. 49, 95-100. doi: 10.1111/j.1600-079x.2010.00774.x

Murch, S. J., Krishnaraj, S., and Saxena, P. K. (2000). Tryptophan is a precursor for melatonin and serotonin biosynthesis in in vitro regenerated St. John's wort (Hypericum perforatum L. cv. Anthos) plants. Plant Cell Rep. 19, 698-704. doi: $10.1007 / \mathrm{s} 002990000206$

Okazaki, M., and Ezura, H. (2009). Profiling of melatonin in the model tomato (Solanum lycopersicum L.) cultivar Micro-Tom. J. Pineal Res. 46, 338-343. doi: 10.1111/j.1600-079X.2009.00668.x

Pape, C., and Lüning, K. (2006). Quantification of melatonin in phototrophic organisms. J. Pineal Res. 41, 157-165. doi: 10.1111/j.1600-079X.2006.00348.x

Ramakrishna, A., Giridhar, P., Jobin, M., Paulose, C. S., and Ravishankar, G. A. (2011). Indoleamines and calcium enhance somatic embryogenesis in Coffea canephora P ex Fr. Plant Cell Tissue Organ Cult. 108, 267-278. doi: 10.1007/s11240-011-0039-z

Ramakrishna, A., Giridhar, P., and Ravishankar, G. A. (2009). Indoleamines and calcium channels influence morphogenesis in in vitro cultures of Mimosa pudica L. Plant Signal. Behav. 4, 1136-1141. doi: 10.4161/psb.4.12.10101

Reiter, R., Tan, D.-X., Zhou, Z., Cruz, M., Fuentes-Broto, L., and Galano, A. (2015). Phytomelatonin: assisting plants to survive and thrive. Molecules 20, 7396-7437. doi: 10.3390/molecules20047396

Rodriguez-Naranjo, M. I., Gil-Izquierdo, Á., Troncoso, A. M., Cantos, E., and García-Parrilla, M. C. (2011). Melatonin: a new bioactive compound in wine. J. Food Comp. Anal. 24, 603-608. doi: 10.1016/j.jfca.2010.12.009

Sanchez-Barcelo, E. J., Mediavilla, M. D., Vriend, J., and Reiter, R. J. (2016). Constituitive photomorphogenesis proten 1 (COP1) and COP9 signalosome, evolutionarily conserved photomorphogenic proteins as possible targets of melatonin. J. Pineal Res. 61, 41-51. doi: 10.1111/jpi.12340

Shi, H., Chen, K., Wei, Y., and He, C. (2016). Fundamental issues of melatonin-mediated stress signaling in plants. Front. Plant Sci. 7:124. doi: 10.3389/fpls.2016.01124

Shi, H., Jiang, C., Ye, T., Tan, D. X., Reiter, R. J., Zhang, H., et al. (2015). Comparative physiological, metabolomic, and transcriptomic analyses reveal mechanisms of improved abiotic stress resistance in bermudagrass [Cynodon dactylon (L). Pers.] by exogenous melatonin. J. Exp. Bot. 66, 681-694. doi: 10.1093/jxb/eru373

Skoog, F., and Miller, C. O. (1957). Chemical regulation of growth and organ formation in plant tissues cultured in vitro. Symp. Soc. Exp. Biol. 11, 118-130.

Stürtz, M., Cerezo, A. B., Cantos-Villar, E., and Garcia-Parrilla, M. C. (2011). Determination of the melatonin content of different varieties of tomatoes (Lycopersicon esculentum) and strawberries (Fragaria ananassa). Food Chem. 127, 1329-1334. doi: 10.1016/j.foodchem.2011.01.093

Sun, Q., Zhang, N., Wang, J., Zhang, H., Li, D., Shi, J., et al. (2015). Melatonin promotes ripening and improves quality of tomato fruit during postharvest life. J. Exp. Bot. 66, 657-668. doi: 10.1093/jxb/eru332

Tal, O., Haim, A., Harel, O., and Gerchman, Y. (2011). Melatonin as an antioxidant and its semi-lunar rhythm in green macroalga Ulva sp. J. Exp. Bot. 62, 1903-1910. doi: 10.1093/jxb/erq378

Tan, D. X., Hardeland, R., and Manchester, L. C. (2012). Emergence of naturally occurring melatonin isomers and their proposed nomenclature. J. Pineal Res. 53, 113-121. doi: 10.1111/j.1600-079X.2012.00979.x

Tan, D.-X., Manchester, L. C., Di Mascio, P., Martinez, G. R., Prado, F. M., and Reiter, R. J. (2007). Novel rhythms of N1-acetyl-N2-formyl5-methoxykynuramine and its precursor melatonin in water hyacinth: importance for phytoremediation. FASEB J. 21, 1724-1729. doi: 10.1096/fj.06$7745 \mathrm{com}$ 
Vigentini, I., Gardana, C., Fracassetti, D., Gabrielli, M., Foschino, R., Simonetti, P., et al. (2015). Yeast contribution to melatonin, melatonin isomers and tryptophan ethyl ester during alcoholic fermentation of grape musts. J. Pineal Res. 58, 388-396. doi: 10.1111/jpi.12223

Wang, L., Zhao, Y., Reiter, R. J., He, C., Liu, G., Lei, Q., et al. (2013), Changes in melatonin levels in transgenic "Micro-Tom" tomato overexpressing ovine AANAT and ovine HIOMT genes. J. Pineal Res. 56, 134-142. doi: 10.1111/jpi.12105

Wei, Y., Hu, W., Wang, Q., Zeng, H., Li, X., Yan, Y., et al. (2016). Identification, transcriptional and functional analysis of heat shock protein $90 \mathrm{~s}$ in banana (Musa acuminata L.) highlight their novel role in melatonin-mediated plant response to Fusarium wilt. J. Pineal Res. doi: 10.1111/jpi.12367. [Epub ahead of print].

Yılmaz, C., Kocadağll, T., and Gökmen, V. (2014). Formation of melatonin and its isomer during bread dough fermentation and effect of baking. J. Agric. Food Chem. 62, 2900-2905. doi: 10.1021/jf500294b

Zhang, L., Jia, J., Xu, Y., Wang, Y., Hao, J., and Li, T. (2011). Production of transgenic Nicotiana sylvestris plants expressing melatonin synthetase genes and their effect on UV-B-induced DNA damage In Vitro Cell. Dev. Biol. Plant 48, 275-282. doi: 10.1007/s11627-0119413-0

Zhao, Y., Tan, D.-X., Lei, Q., Chen, H., Wang, L., Li, Q.-T., et al. (2013). Melatonin and its potential biological functions in the fruits of sweet cherry. J. Pineal Res. 55, 79-88. doi: 10.1111/jpi.12044

Conflict of Interest Statement: The authors declare that the research was conducted in the absence of any commercial or financial relationships that could be construed as a potential conflict of interest.

Copyright (c) 2016 Erland, Chattopadhyay, Jones and Saxena. This is an openaccess article distributed under the terms of the Creative Commons Attribution License (CC BY). The use, distribution or reproduction in other forums is permitted, provided the original author(s) or licensor are credited and that the original publication in this journal is cited, in accordance with accepted academic practice. No use, distribution or reproduction is permitted which does not comply with these terms. 